\title{
Investigation and Countermeasures Analysis of College Students' Cognition on Online Lending under the Background of Mobile Internet
}

\author{
Jun Leng ${ }^{1}$, Yong $\mathrm{He}^{2}$, Xiaotong You ${ }^{2}$ \\ ${ }^{1}$ Student Affairs Office of Sichuan Agricultural University, Chengdu, Sichuan, China \\ ${ }^{2}$ College of Animal Science and Technology, Sichuan Agricultural University, Chengdu, Sichuan, China
}

Keywords: Online Lending, Cognition On Online Lending, Countermeasure Research.

\begin{abstract}
Online lending is a newly sprouted thing emerging with the rapid development of Internet. In recent years, it causes a lot of controversies. Based on questionnaire survey and interviews with college students, this paper studies students' understanding and participation in online lending, as well as their attitudes towards online lending and influencing factors. Afterwards, policy recommendations on the standardization and improvement of online lending industry and the improvement of college students' cognitive abilities are put forward.
\end{abstract}

\section{Introduction}

With the popularity of mobile phones and the mobile Internet, college students' daily learning and life increasingly rely on mobile Internet. In addition, contemporary college students have curiosity and exploration desire for new things. These factors lead to their non-traditional consumption behaviors. Online lending, as a newly emerging thing accompanying the development of Internet finance, is a double-edged sword. It provides financial support for college students' reasonable demands for learning, consumption and entrepreneurship, but at the same time, it also causes many risks and hidden dangers. In recent years, a series of campus tragedies caused by online lending are reported, which bring troubles for colleges, students as well as their parents, and produce a very bad impact on the society. In April 2016, the Ministry of Education and the China Banking Regulatory Commission jointly issued The Notice on Strengthening the Risk Prevention and Education Guidance of Unhealthy Online Lending in Campus, and the concept of "campus online lending" began to appear in official documents. How to effectively control online lending and make it to play its positive role, and guide college students to establish the correct consumption concept and moderate consumption behaviors? These are realistic topics facing current ideological and political education in colleges and universities. This research is carried out on the basis of many problems exposed in college students' online lending consumption behaviors. It investigates students from Sichuan $\mathrm{N}$ University, analyzes their cognition of online lending, and puts forward to specific policy recommendations.

\section{Investigation organized}

In this study, network questionnaire was used. 235 students were randomly selected from various majors and grades, including 115 male students and 120 female students. Among them, 191 were undergraduates; 44 were graduates, including master and doctoral students. 133 students came from urban families, while 105 students came from rural families. There are 17 questions which were divided into 4 aspects in the survey. Questions include students' understanding and participation in online lending, as well as their attitudes and influencing factors of online lending. On the basis of questionnaire survey, targeted interviews were conducted. Researchers also referred to relevant documents and finished the investigation report. 


\section{Investigation results}

Students' understanding on online lending. 97.87\% students "have heard about online lending". Only $2.13 \%$ of the students have not heard of it. $19.57 \%$ students express that they "do not understand the online lending"; $72.77 \%$ students express that they "know something about the online lending"; only $7.66 \%$ students believe they "know online lending very well". For the question of "have you ever heard negative reports on online lending", the proportions of "occasionally heard" and "often heard" are similar: $50.21 \%$ and $47.23 \%$. Only $2.55 \%$ students have not heard these news. "The channel of knowing online lending" can be arranged from high proportion to low ratio as follows: "network channel" (81.7\%), "classmates and friends" (54.75\%), "family members" (39.15\%) and "others" (5.11\%). (Note: this problem is multiple choice, so the total proportion is more than $100 \%$ ).

The cognition of online lending. Up to $82.98 \%$ of the respondents believe that "online lending is not safe". The proportion of students who believed online lending is "safe" is $16.17 \% .0 .85 \%$ of these students hold that the security of online lending is "hard to say". For the question of parents' support, up to $75.32 \%$ of respondents express that their parents will object. The proportion of "parents will support but worry about it" is $17.02 \%$. The ratio of "parents will support and will not worry about it" is $5.53 \%$. The proportion of "unclear" is $2.13 \%$. The proportions of online lending's advantages are "convenient and fast", accounting for 82.98\%; "simple operation" accounting for 68.94\%; "low threshold" accounting for $62.98 \%$. "high cost performance" accounting for 13.62\%; "low interest rate" accounting for $12.34 \%$, and others, accounting for $2.13 \%$. The disadvantages of online lending are "have risks" (61.28\%), be afraid of network fraud (53.62\%), high interest rate (31.49\%), low transparency (14.89\%), incomplete mechanism (9.36\%) and others (2.98\%) (Note: questions about advantages and disadvantages are multiple choice, so the total proportions are more than $100 \%$ ).

The participation in online lending. For the question of "whether to try online lending if necessary", the proportions of "yes" and "no" are almost the same. The proportion of the former is slightly higher than that of the latter, which are $52.77 \%$ and $47.23 \%$ respectively. 38 people express that they "have consumed online lending", accounting for $16.17 \%$. The ratio of students who "have not consumed online lending" is $83.83 \%$. For "whether your classmates have consumed online lending", $10.21 \%$ students select "yes", $14.89 \%$ students select "no", and $74.90 \%$ students say they "do not know". Among the 38 people who have consumed online lending, the highest proportion of "online lending limit" is "lower than1000 yuan", accounting for 44.74\%; the rest choices are 1000 to 2000 yuan (26.32\%), 2001 to 3000 yuan (21.05\%), and 3000 yuan or more (7.89\%). 52.63\% of the students choose the online lending period "from three months to half a year"; $23.68 \%$ choose "less than three month"; $18.42 \%$ choose "from six months to one year". The proportion of "one year or more" is $5.26 \%$. The purpose of choosing online lending are: "online shopping and entertainment" accounts for $42.11 \%$; "living consumption" accounts for $26.32 \%$, "learning and training" account for $15.79 \%$; "tourists" accounts for $10.53 \%$; "others" account for $0.85 \%$.

Overall attitudes towards online lending and influencing factors. In the aspect of "influencing factors", the proportions of "friends and schoolmates' attitude" and "family members' attitude" are basically the same, respectively $61.28 \%$ and $60 \%$. "Network public opinion and evaluation" accounts for $42.98 \%$; "others" accounts for $5.11 \%$. (Note: this problem is multiple choice, so the total proportion is more than $100 \%)$. As for the question of "will you continue to consume online lending", among the 38 respondents who have consumed online lending, the proportions of "yes" and "no" are almost the same, which are $36.84 \%$ and $34.21 \%$ respectively, and the proportion of "unclear" is $28.95 \%$. The highest proportion of the overall attitude towards online lending is "will choose it if urgently needed" (48.94\%). The rest choices are "high risk" (36.17\%), "object to online lending" (9.36\%) and "advocate consumption" (5.53\%).

\section{Results analysis}

Analysis of students' understanding. Up to $97.87 \%$ students have heard about online lending; more than $80 \%$ students know online lending; $81.7 \%$ students know it from network. It is very closely 
related to the digitalized life style of "the generation after 1995". These college students are "network aborigines". The Internet has characteristics of fast dissemination, wide coverage, large amount of information and strong guidance. It imperceptibly influences the values and consumption patterns of college students while transmitting information. The rapid development of mobile Internet also contributes to the penetration of online lending. Up to $97.45 \%$ of college students have heard about the negative reports of online lending, which is closely related to the "barbaric growth" of online lending industry in recent years; it is the result of the lack of legal regulation.[1] Compared with online information, offline channels like family, friends and classmates have little effects on college students. The idea exchange and risk aversion mechanisms of traditional channels have lost their efficacy to a certain extent.

Analysis of students' cognition of online lending. Up to 82.98\% respondents believe that online lending is not safe, which is highly consistent with the fact that $97 \%$ college students have heard negative reports about online lending. This shows that the extensive publicity and education activities carried out by schools and all levels of departments have played a role in warning. Parents who support consumption on online lending are far less than parents who object it; some people still worry about that even if they support their children. Parents are more cautious about online lending, and their life styles are relatively traditional. Another reason is that they have heard a lot of negative reports and public opinions about online lending. Convenient, simple operation and low threshold rank the top three merits of online lending and occupy high proportions, which is because that the rapid development of Internet technology has greatly changed people's consumption habits, and brought new consumer channels like network shopping and network lending. According to the research, the main consumption channel for more than $80 \%$ of college students is online shopping [2]. Students born after 1995 love fashion and fresh. They form an important part of network consumption. Staying at home, you can purchase goods from all over the world by moving your fingertips. This consumption pattern is greatly favored by college students. Many online lending companies are established to meet these requirements of college students. Risks, network fraud and high interest rate are the top three shortcomings of online lending. This is consistent with previous analysis on negative reports of online lending. It shows that the barbarism growth of online lending has brought many hidden dangers.

Analysis of the participation in online lending. Through the production of a large number of cultural products in mass media, a "simulation environment" is created. The spread of consumption ideology make students believe, "if you buy the product, you will have a certain cultural meaning and life value; the embodiment of this commodity is the meaning and value. If you miss the product, you will regret" [3]. But students' limited financial resources cannot meet their growing consumption demands created by mass media, fashion goods and peer groups. Online lending platforms solve this problem. In this survey, more than half of the college students will try online lending; $26.38 \%$ students have consumed it. $42.11 \%$ of their consumptions are "online shopping and entertainment". 92.11\% students have credit demands up to 3000 yuan; 52.63\% students choose the lending period "from three months to half a year". These data are consistent with the characteristics of college students. Besides online shopping and entertainment, they have diversified consumption demands such as living consumption, learning, training and tourism. This shows that college students have higher credit demands, which leave room for formal, standard campus online lending business.

Analysis of influencing factors and overall attitude. "Friends and classmates' attitude" and "family members' attitude" affect the same proportion of college students, indicates that their living environment has great influence on college students' consumption concept. $36.84 \%$ online lending consumers will continue to use online lending; $34.21 \%$ express they would not use in the future; $48.94 \%$ choose that they will use it if necessary. A large proportion of students believe that online lending has high risk, and choose to object it. It is consistent with previous analysis on online lending's advantages and disadvantages. College students have rigid demands, but they still doubt the security of online lending. It indicates directions for the development of online lending industry and the strengthening of school education for relevant departments. 


\section{Policy suggestions}

Strengthening legal restriction and industry supervision. In recent years, the development of campus online lending companies is in the state of barbaric growth. According to the reports in China Youth Daily, there are three main channels for students to get loans: the first channel is installment buying platforms, such as Qufenqi and Renfenqi; the second channel is P2P lending platforms, such as Toutoudai and Mingxiaodai; the third is credit services provided by traditional business platforms such as Jingdong and Taobao [4]. This research shows that college students have demands for credit, so we cannot refuse online lending completely. Rational regulations are needed to regulate the behaviors of both parties, in order to protect the healthy development of network financial industry and the legitimate rights and interests of consumers.

On the one hand, we should strictly regulate online lending companies. First, the authority should standardize the examination and approval links of establishing online lending companies. Examination and approval of financial regulatory agencies, as well as registration in the industry and commerce department are necessary. Loan business must be carried out under the permission of the authority. Second, online lending company must audit loans provided for college students and take responsibility. Third, it is necessary to regulate the interest rate of online lending through the law. Fourth, the punishment procedures must be regulated. The online lending company could not take extreme actions to collect the debt; they cannot violate the privacy of the debtor. The company would be prosecuted if it causes debtor's pecuniary loss or damage to reputation and person. [5] Fifth, the publicity of online lending companies should be standardized; induction and false propaganda should be prohibited. Sixth, charges except interest rates, such as "information fee", and "service charges" should be cancelled.

On the other hand, it is necessary to strictly regulate the behaviors of college students. One research shows that: "a main body personality without the capacity of civil liability is incomplete" [6]. Students are over eighteen years old, and have clear judgments on things. But they cannot earn their life cost through labor. They do not have the ability of undertaking economic responsibility, so their behavioral capacities should be limited. First, it is necessary for college students to get their guardians' consent. Second, it is necessary to limit the total amount of college students' online lending. Third, a unified platform system about online lending insurance, personal bankruptcy and loan information should be established, in order to form a more perfect online lending risk prevention system for college students together with above systems. [1]

Setting up the correct direction of public opinion and creating a harmonious atmosphere. First, we must purify the campus environment, and resolutely prohibit the advertising and publicity of bad online lending activities. The school authority should also prohibit the infiltration of online lending business through employing part-time workers and sponsor campus activities. We should actively carry out activities to carrying forward the excellent Chinese traditional culture, and help students to lighten their obsession of material symbols. The school should also encourage students to walk into the society through social practice, help them to understand the society and realize that it is difficult to live happy lives; their responsibility will be cultivated during this process [7]. Secondly, we should combine traditional media and the new media to establish advantages in public voice, in order to strengthen ideological guidance, and guide students to establish healthy consumption ideas, inherit traditional virtues, as well as form credit concepts and risk awareness. With the full use new media' interactive functions, the subjective initiative of college students can be promoted. Then the consumption problems can be discussed and interpreted from multiple perspectives; students will form objective and rational opinions. [8] Furthermore, college students' reasonable consumption demands should be noticed. Formal financial enterprises should be encouraged to enter the campus, so as to provide financial services for students and guide students to consume financial products rationally. [9] Both formal financial institutions and students can get benefits. Finally, we must establish a sound funding system, strictly implement various national subsidy policies, and offer loans and grants on the basis of careful evaluation. Families with financial difficulties should be supported accurately, in order to prevent students to apply for bad loans because of financial 
difficulties in the family.

Strengthening value guidance and setting up correct concepts. The deficit spending demands and credit consumption desire of college students should be reduced in proper ways. First, we should strengthen the education of consumption conception, guiding students to set up positive and healthy consumption views, and to actively resist bad ideas of excessive consumption and conspicuous consumption. Second, we should strengthen the credit education, guiding students to establish the concept of credit. Students need to understand the importance of personal credit records; they should fully estimate their repayment ability, predict adverse impact, then cherish and actively maintain their good credit record [10]. Third, we need to strengthen legal education, help students enhance law awareness and vigilance; they should pay attention to personal information protection, and improve their judgment ability. Advertisements and instigation should be carefully identified; illegal credit should be resisted. The school should also teach students, how to use legal weapons to protect themselves. When they are involved in bad credit business, or their personal rights and interests are infringed, they should seek legal support and protection in time.

\section{Acknowledgement}

Fund Project: This paper is one of the outcomes of the research, Developing New Working Patterns on Students Affairs to Adapt to the Construction of World-class Universities and First-class Disciplines, which is supported by the Foundation for Key Research Projects on Innovations in Instructors' Work in Sichuan Agricultural University.

\section{References}

[1] P. Liang, Controlling the risk of college students' online lending through legal tools, J. Journal of Chinese Youth Social Science. 9 (2016).

[2] M.H. Lin, Investigation and analysis of consumer behaviors of university students in online lending and guiding strategy, J. Ideological \& Theoretical Education. 5 (2017).

[3] N. Wang, The Sociology of Consumption, Social Sciences Academic Press (China), Beijing, 2011.

[4] Z.X. Pan, The crazy invasion of campus online lending: a blessing or a curse? J. China Youth Daily. 3 (2016).

[5] S. Pang, Y. Cheng, Analysis on reasons of college students' online lending and risk control, J. Ideological \& Theoretical Education. 2 (2017).

[6] Y. Sun, Civil liability ability in multiple contexts, J. Northern Legal Science, 1 (2007).

[7] S. Pang, H. Zhao, Analysis on education about college students' consumption ethics under the theory of simulacra, J. The Party Building and Ideological Education in Schools, 2015 (12).

[8] X. Wei, The role of new campus media in the education of college students' consumption, J. Studies in Ideological Education. 4 (2016).

[9] D.Y. Huang, Y.M. Du, the activity of "publicizing financial knowledge in campus" is officially launched, J. China Youth Daily. 11 (2016).

[10] Y.Q. Li, Problems in state-subsidized student loan system and the construction of university credit framework system, J. Accounting and Financial of Institution. 5 (2006). 